\title{
Study on Restricting Factors about Production Scale based on Grey Correlation Degree in Wulongquan Mine
}

\author{
D. Yin, L.H. Ke \\ School of Resources and Environment Engineering \\ Wuhan University of Science and Technology \\ Wuhan Hubei, China
}

\begin{abstract}
According to the actual demand of enlarging production scale and the present production condition in wulongquan mine, the production costs is stubbornly high and becomes a key factor of restricting production scale. In order to find out the restricting factors of production scale, grey slope correlation degree has been adopted respectively to analyze the grey incidence order between production scale and the influence factors such as materials costs, spare parts costs, energy costs, labour costs, repair costs and depreciation costs. And what's more, the key restricting factors of production scale have been determined to be repair costs, labour costs and materials costs by describing objectively the relationship between production scale and influence factors. The analyzing result is in line with the actual situation and the production scale of mine can be drawn up according to the basic information.
\end{abstract}

Keywords-open mine; production management; production scale; slope correlation degre; restricting factors

\section{INTRODUCTION}

The production scale is one of the important factors to make decisions in mine enterprises. Not only does it influence the selection about the types and quantity of mining equipments, but it affects the number of staff and materials. And what's more, the production scale also affects investment, production costs and economic benefits. Reasonable determination of mine production scale is one of the critical works in mining enterprises. In general, market demand for minerals, mining technology and economic conditions are often considered comprehensively to optimize production scale [1].The technical and economic factors include mining intensity, quantity of workplace and its capacity, production capacity of every process, market capacity, capital, cost control and efficiency expectations, etc. [2]. For most minerals, the market capacity is very large. So the total demand for minerals is much higher than the output of any mining enterprises. Thus the output of any mining enterprise can not affect market price of minerals. Meanwhile, under the market economy mineral prices vary widely and are not easy to predict. Although the prices of minerals can indirectly influence the adjustment and planning of production scale about mining companies, mining enterprises determine their production scales based on technical conditions and production cost factors.

There are some mining enterprises having complex resource occurrence situation and poor mining conditions. These mining enterprises are often faced with the problem such as 'production cost is close to product prices'. At the same time, production scales of mining enterprises are restricted and difficult to be improved with the gradual rising trend in production costs. In order to maintain normal production and operation of mine, production capacity must be increased while production costs should be reduced reasonably. Considering economic benefits brought by the large-scale production of mining enterprises, the relationship between production capacity and the influence factors of production cost should be researched to find out the key factors of restricting mine production scale. Furthermore, the reasonable production scale can be determined.

In this paper, according to the actual demand of enlarging production scale and the present production condition in wulongquan mine, the grey slope correlation degree has been adopted respectively to calculate the grey incidence order between production scale and the influence factors of production cost such as materials costs, spare parts costs, energy costs, labor costs, repair costs and depreciation costs. And what's more, the important factors of restricting production scale have been determined objectively so that the mining enterprise can draw up and optimize its plan of production capacity.

\section{ANALYTICAL METHODS AND ANALYSIS PROCEDURES}

At present, there are some researches of the mine production scale in optimization focused on reserves, market demand, technology and economic condition [3]. In these studies, although a number of technical and economic factors influencing production scale have also been mentioned, there are a few of researches emphasizing on the restricting factors of production capacity. In order to achieve the economic benefits from large-scale production, the key factors of restricting production capacity must be analyzed from the view of production cost factors based on the actual situation. In general, the production capacity and cost factors affect each other. And what's more, their relationship will vary with time. By analyzing the close relationship between production capacity and cost factors, the key restricting factors of production capacity can be found out. According to the analysis result, the measures of enlarging production scale can be drawn up.

Grey correlation degree analytical method, a multivariate objective statistical analysis method, can be used to describe 
the strong-weak degrees and orders of the relationship between factors based on less data sample values. The modeling method can be adopted to research the realistic dynamic developing trend by analyzing the changes of behavior characteristics based on time[4]. So the grey correlation degree analytical can be used to analyze the restricting factors of production scale. At present, there are some algorithms of grey correlation degree such as Deng's relational degree, grey absolute correlation degree, $\mathrm{T}$ type correlation degree, slope correlation degree and $\mathrm{B}$ type association degree. In these algorithms, the grey slope absolute correlation degree can describe the varying trend in change rate about two time sequences.

The calculation procedure and step of grey correlation analysis method are as follows:

(1) Definition of reference sequence $X_{0}$ and comparison sequence $X_{i}$

Reference sequence is defined as $X_{0}=\left\{x_{0}(k)\right\}, k=1,2, \cdots, n$ while comparison sequences are defined as $X_{i}=\left\{x_{i}(\mathrm{k})\right\}, i=1,2, \cdots, \mathrm{m}, k=1,2, \cdots, n$.

(2) Dimensionless process and methods

The function(1) has been adopted to deal with the sample value of reference sequence $X_{0}$. At the same time, the function (2) has been used to deal with the sample value of comparison sequence $X_{i}$. All the sequences can be unified in the some space without the effects of statistical data in dimension.

$$
\begin{aligned}
& x_{0}^{\prime}(k)=\frac{x_{0}(k)}{x_{0}(1)}, k=1,2, \cdots, n \\
& x_{i}^{\prime}(k)=\frac{x_{i}(k)}{x_{i}(1)}, i=1,2, \cdots, \mathrm{m}, k=1,2, \cdots, n
\end{aligned}
$$

where $x_{0}(k)$ is the non-dimensional values of reference sequence $X_{0}$ at the time point $k, x_{\mathrm{i}}(k)$ is the non-dimensional values of comparison sequence $X_{i}$ at the time point $k, x_{0}(1)$ is the sample value of reference sequence $X_{0}$ at the time point $1, X_{\mathrm{i}}(1)$ is the sample value of comparison sequence $X_{i}$ at the time point 1 .

(3) Calculation of grey correlation coefficients $\xi_{0 i}(k)$ based on slope correlation method

The functions (3)-(5) have been adopted to calculate the grey slope correlation coefficients $\xi_{0_{i}}(k)$ between the comparison sequence $X_{i}$ and reference sequence $X_{0}$.

$$
\xi_{0 i}(k)=\frac{1}{1+\left|\frac{\Delta x_{0}^{\prime}(k)}{x_{0}^{\prime}(k+1)}-\frac{\Delta x_{i}^{\prime}(k)}{x_{i}^{\prime}(k+1)}\right|}
$$

$$
\begin{aligned}
& \Delta x_{0}^{\prime}(k)=x_{0}^{\prime}(k+1)-x_{0}^{\prime}(k) \\
& \Delta x_{i}^{\prime}(k)=x_{i}^{\prime}(k+1)-x_{i}^{\prime}(k)
\end{aligned}
$$

(4) Calculation of grey slope correlation degree $r_{0 i}\left(X_{0}^{\prime}, X_{i}^{\prime}\right)$

According to the function (6), the grey slope correlation degree $r_{0 i}\left(X_{0}^{\prime}, X_{i}^{\prime}\right)$ between the comparison sequence $X_{i}$ and reference sequence ${ }^{X_{0}}$ can be calculated.

$$
r_{0 i}\left(X_{0}^{\prime}, X_{i}^{\prime}\right)=\frac{1}{n-1} \sum_{k=1}^{n-1} \xi_{0 i}(k)
$$

(5) Determination of restricting factors about production scale

By comparing the correlation degree between the comparison sequence $X_{i}$ and reference sequence $X_{0}$, restricting cost factors about production scale have been found out. The larger the grey slope correlation degree is, the closer the corresponding factors are. So the corresponding factors are the key factors of restricting production scale. According to the above analysis, reasonable plans of enlarging production scale and reducing the production cost will be drawn up based on determination of the restricting factors.

\section{ANALYSIS OF THE FACTORS ABOUT RESTRICTING PRODUCTION SCALE}

Wulongquan mine is a large important production base of limestone, belonging to Wuhan iron and steel group corporation. At present, production capacity of wulongquan mine has not met the demand of Wuhan iron and steel group corporation. There are some characters such as numerous widely-distributed faultage, diversification of ore grade, developed karsts and fissures within the deposit and numerous interlayer in wulongquan mine[6]. So the complexity of deposit exploitation is increasing while production costs of the mine enterprise are increasing gradually. The affecting factors of production costs are materials costs, spare parts costs, energy costs, labor costs, repair costs and depreciation costs. During different production period, wulongquan mine has experienced a exploitation process that mining transportation system has been adjusted from single rail transport system to rail - car transport one. During this period, the relation between production scale and these factors varies differently. According to the demand of enlarging production scale, slope correlation degree has been adopted to analyze the restricting factors of production scale from the view of production cost.

A series of data about mine production costs and production quantity has been collected. The production quantity sequence is defined as reference sequence while materials costs, spare parts costs, energy costs, labor costs, repair costs and depreciation costs are defined as comparison sequences. Relative rates of change about each sequence in every time are calculated after non-dimensional process. The non-dimensional values have been showed in the Table 1 . And what's more, the histogram and grey correlation change are shown in Figure 1 and Figure 2. The slope correlation 
coefficients between the reference sequence $X_{0}$ and comparison sequences $X_{i}$ have been calculated according to formula (3)-(6). At last, the correlation degree between the comparison sequence $X_{i}$ and reference sequence $X_{0}$ can be obtained (in the Table 2) and compared. The larger the grey slope correlation degree $r_{0 i}\left(X_{0}^{\prime}, X_{i}^{\prime}\right)$ is, the closer the corresponding factors are.

TABLE I. DIMENSIONLESS PROCESS AND RESULTS OF CORRESPONDING DATA IN WULONGQUAN MINE.

\begin{tabular}{|c|c|c|c|c|c|c|c|c|}
\hline Time & $\mathbf{2 0 0 6}$ & $\mathbf{2 0 0 7}$ & $\mathbf{2 0 0 8}$ & $\mathbf{2 0 0 9}$ & $\mathbf{2 0 1 0}$ & $\mathbf{2 0 1 1}$ & $\mathbf{2 0 1 2}$ & $\mathbf{2 0 1 3}$ \\
\hline production scale $x_{0}^{\prime}(k)$ & 1.000 & 0.987 & 0.878 & 0.808 & 0.970 & 0.918 & 0.948 & 0.955 \\
\hline materials costs $x_{1}^{\prime}(k)$ & 1.000 & 0.943 & 1.404 & 1.504 & 2.149 & 1.826 & 2.103 & 2.128 \\
\hline spare parts costs $x_{2}^{\prime}(k)$ & 1.000 & 0.773 & 0.697 & 0.618 & 0.645 & 0.790 & 0.597 & 0.846 \\
\hline repair costs $x_{3}^{\prime}(k)$ & 1.000 & 0.934 & 1.002 & 0.932 & 1.199 & 1.201 & 1.269 & 1.570 \\
\hline energy costs $x_{4}^{\prime}(k)$ & 1.000 & 0.717 & 2.119 & 2.070 & 1.775 & 1.279 & 1.263 & 1.286 \\
\hline labor costs $x_{5}^{\prime}(k)$ & 1.000 & 1.230 & 1.435 & 1.725 & 2.122 & 2.011 & 2.133 & 1.625 \\
\hline depreciation costs $x_{6}^{\prime}(k)$ & 1.000 & 1.705 & 2.121 & 2.072 & 3.355 & 3.374 & 4.459 & 2.633 \\
\hline
\end{tabular}

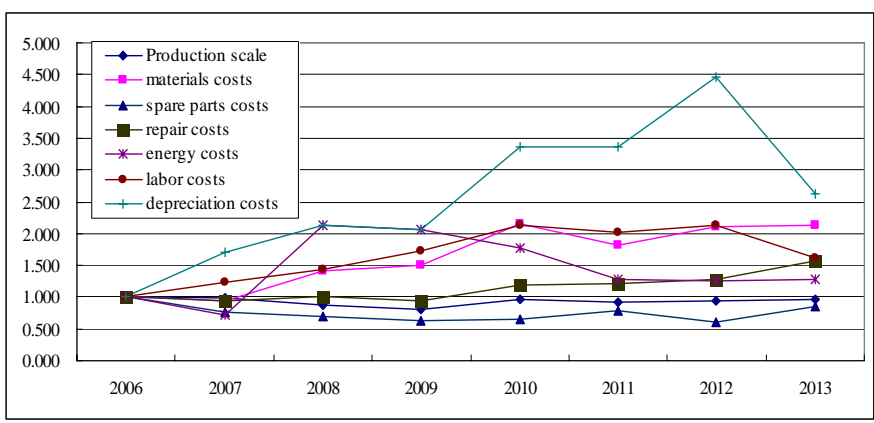

FIGURE I. GREY CORRELATION ANALYSIS ABOUT PRODUCTION SCALE AND COST FACTORS.

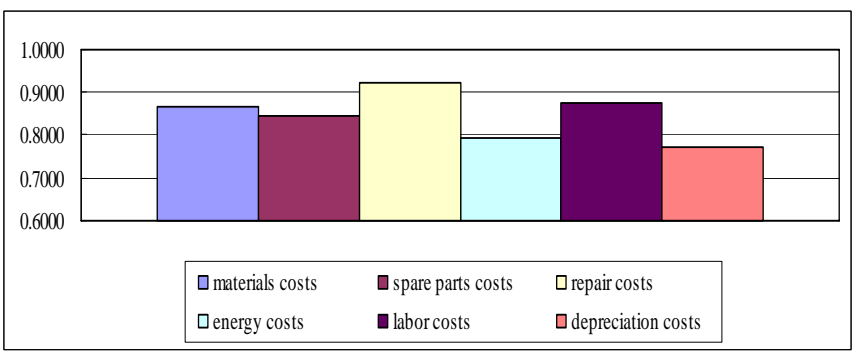

FIGURE II. GREY CORRELATION DEGREE BETWEEN PRODUCTION SCALE AND COST FACTORS.
TABLE II. THE SLOPE CORRELATION COEFFICIENTS AND THE GREY CORRELATION DEGREE.

\begin{tabular}{|c|c|c|c|c|c|c|c|c|c|c|}
\hline Time & $\mathbf{2 0 0 6}$ & $\mathbf{2 0 0 7}$ & $\mathbf{2 0 0 8}$ & $\mathbf{2 0 0 9}$ & $\mathbf{2 0 1 0}$ & $\mathbf{2 0 1 1}$ & $\mathbf{2 0 1 2}$ & $\mathbf{2 0 1 3}$ & $r_{0 i}\left(X_{0}^{\prime}, X_{i}^{\prime}\right)$ & $\begin{array}{l}\text { Grey } \\
\text { correla } \\
\text { tion } \\
\text { degree }\end{array}$ \\
\hline$\Delta x_{0}^{\prime}(k)$ & -0.013 & -0.109 & -0.070 & 0.162 & -0.052 & $\begin{array}{c}0.03 \\
0\end{array}$ & 0.008 & & & \\
\hline$\Delta x_{1}^{\prime}(k)$ & -0.057 & 0.460 & 0.101 & 0.645 & -0.323 & $\begin{array}{c}0.27 \\
8\end{array}$ & 0.025 & & & \\
\hline$\Delta x_{2}^{\prime}(k)$ & -0.227 & -0.076 & -0.079 & 0.028 & 0.144 & $\begin{array}{c}- \\
0.19 \\
-\end{array}$ & 0.249 & & & \\
\hline$\Delta x_{3}^{\prime}(k)$ & -0.066 & 0.069 & -0.070 & 0.267 & 0.002 & $\begin{array}{c}0.06 \\
7\end{array}$ & 0.301 & & & \\
\hline$\Delta x_{4}^{\prime}(k)$ & -0.283 & 1.402 & -0.049 & -0.295 & -0.495 & $\begin{array}{c}- \\
0.01 \\
-1\end{array}$ & 0.023 & & & \\
\hline$\Delta x_{5}^{\prime}(k)$ & 0.230 & 0.204 & 0.290 & 0.397 & -0.111 & $\begin{array}{c}0.12 \\
2\end{array}$ & -0.508 & & & \\
\hline$\Delta x_{6}^{\prime}(k)$ & 0.705 & 0.416 & -0.049 & 1.282 & 0.019 & $\begin{array}{c}1.08 \\
5\end{array}$ & -1.826 & & & \\
\hline$\xi_{01}(k)$ & 0.9584 & 0.6256 & 0.8688 & 0.8145 & 0.9120 & $\begin{array}{c}0.89 \\
31\end{array}$ & 0.9963 & 6.0686 & 0.8669 & 3 \\
\hline$\xi_{02}(k)$ & 0.8239 & 0.9883 & 0.9671 & 0.8651 & 0.7826 & $\begin{array}{c}0.78 \\
33\end{array}$ & 0.7097 & 5.9200 & 0.8457 & 4 \\
\hline$\xi_{03}(k)$ & 0.9495 & 0.8446 & 0.9909 & 0.9211 & 0.9470 & $\begin{array}{c}0.97 \\
68\end{array}$ & 0.8136 & 6.4435 & 0.9205 & 1 \\
\hline$\xi_{04}(k)$ & 0.7877 & 0.3263 & 0.9467 & 0.7444 & 0.8163 & $\begin{array}{c}0.95 \\
66\end{array}$ & 0.9899 & 5.5678 & 0.7954 & 5 \\
\hline$\xi_{05}(k)$ & 0.8041 & 0.7834 & 0.7803 & 0.9712 & 0.9983 & $\begin{array}{c}0.97 \\
25\end{array}$ & 0.8023 & 6.1121 & 0.8732 & 2 \\
\hline$\xi_{06}(k)$ & 0.5819 & 0.7382 & 0.9468 & 0.7052 & 0.9436 & $\begin{array}{c}0.77 \\
56\end{array}$ & 0.7054 & 5.3968 & 0.7710 & 6 \\
\hline
\end{tabular}

From the above analysis, repair costs, labor costs and materials costs are key factors of affecting production scale because the three grey slope correlation degrees are larger. In recent years, repairs and maintenance of equipment have frequently occurred while the repair costs varied closer with the change of production quantity because of the aging mine equipment in different degrees. So the condition of the process equipment is a key factor of enlarging the production capacity. In addition, labor costs and material costs also varied synchronously with production capacity. As a result, repairs costs, labor costs and material costs are the major factors of limiting production capacity.

\section{CONCLUSIONS}

(1) According to the characteristics of statistical data, the slope correlation algorithm is used to analyze grey incidence degrees between production scale and the influence factors of production cost such as materials costs, spare parts costs, energy costs, labor costs, repair costs and depreciation costs. The effect of cost factors to production scale has been reflected reasonably.

(2) In order to correctly analyze the factors of restricting production scale, all the sequences can be unified in the some space based on dimensionless process. Doing by this, the discrepancy of different dimensions can be eliminated.

(3) The key restricting factors of production scale have been determined to be repair costs, labor costs and materials 
costs based on the statistical data in wulongquan mine according to slope correlation analysis. The analyzing result is in line with the actual situation.

\section{ACKNOWLEDGEMENT}

This work was supported by the National Natural Science Foundation of China under Grant No.51204127.

Li-hua $\mathrm{Ke}$ is the corresponding author to provide phone: 15337102008; fax:027-68862876;e-mail: 413404880@ qq.com).

\section{REFERENCES}

[1] Zhang You-di \& Ji Chang-sheng. Comprehensive Optimization Of Production Rate and Related Decision-Making Factors For Large Mines. Journal of China University of Mining \& Technology. 29,pp.15-19,2000.

[2] Zhang Zhi-ming, Cai Qin-xiang, Zhou Wei, Wang Bo-wen \&Wei Hua .Scale Model to Determine the Open Pit Production. Metal Mine, 11.pp:5-8,68,2011.

[3] Yu Run-cang, Mining Engineer's Handbook, Metallurgical Industry Press: Beijing, pp:65-68, 2009

[4] Ye,Y.Ch., Ke, L.H.\& Huang, D.Y.Technologies of Comprehensive Evaluation and Its Application], Metallurgical Industry Press: Beijing, pp:165-166, 2006

[5] Lv Feng, Liu xiang \&Liu Quan. The Theory of Gray Relative Analysis and it's New Research.Journal of Wuhan University of Technology. 2( 22 )pp:41-43,47,2000.

[6] KE Li-hua, YE Yi-cheng.Study on production problems and measures for Wulongquan Mine. Industrial Minerals and Processing,7(43),pp 37$39,49,2014$. 